\title{
Teamwork - A Success Factor of Knowledge Management for Faculty Development: A Case Study
}

\author{
Johnny Chin Fui Chung, Yip Mum Wai, Member, IACSIT, Dominic Lau, and Ahmad Rahman Songip
}

\begin{abstract}
The objective of this study is to investigate the success factor and positive impact of Knowledge Management (KM) implementation in higher learning institutions. The paper presented the success factor, i.e. teamwork of KM implementation at Tunku Abdul Rahman College (TARC), Malaysia. A case study was conducted at TARC to examine the positive impact of teamwork in KM implementation. Data were collected through structured interviews. The findings revealed that teamwork was a success factor for KM implementation that brought a positive impact to TARC. However, the results of this qualitative survey may have some inherent limitations in term of validity. Further empirical research is recommended in this study in order to validate the findings. A survey research is highly recommended.
\end{abstract}

Index Terms-Positive impact, success factor, team work.

\section{INTRODUCTION}

In the knowledge-based economy, knowledge has become one of the most valuable resources of an organisation. Choochote (2012) and Kefela (2010) state that managing knowledge is the foundation issue for sustainable competitive advantage [1], [2]. Thus, the practice of Knowledge Management (KM) is relevant and essential in higher learning institutions. However, most organisations have a misconception that $\mathrm{KM}$ is only about information technology; therefore, many of them have faced a lot of challenges in implementing KM due to the less effort on soft element, i.e. people aspect. Therefore, the main purpose of this study is to examine the success factor from the people aspect, i.e. team work, and the positive impact it has on higher learning institutions.

\section{LITERATURE REVIEW}

According to a study conducted by American Productivity and Quality Center's International Benchmarking Clearinghouse, one of the success factors of effective transfer of knowledge and best practices in organisations, such as

Manuscript received September 12, 2012; revised December 20, 2012.

Johnny Chin Fui Chung is with the School of Social Science and Humanities, Tunku Abdul Rahman College, Kuala Lumpur, Malaysia (e-mail: chinfc@mail.tarc.edu.my).

Yip Mum Wai is with the School of Technology, Tunku Abdul Rahman College, Kuala Lumpur, Malaysia (e-mail: yipmw@mail.tarc.edu.my).

Dominic Lau is with the Applied Research Centre, UCSI University, Kuala Lumpur, Malaysia (e-mail: dominiclauhc@gmail.com).

Ahman Rahman Songip is with the Transformation and Risk Management Division, Universiti Teknologi Malaysia, Kuala Lumpur, Malaysia (e-mail: ahmadrx08@gmail.com).
Arthur Anderson, Chevron Corporation, Dow Chemical, Hughes Space and Communication, Kaiser Permanente, Price Waterhouse, Sequent Computers, Skandia APF, Texas Instruments, and National Security Agency, is the importance of the team [3].

Traditional approaches, such as working alone or in informal networks, are being replaced by organised teamwork, learning and knowledge. This is evident in the Boeing Company, a company that is considered a leader in the field of $\mathrm{KM}$ where its team members are networked together according to roles, tasks and project deliverables, and they have access to an electronic library of best practices that can be shared and updated on a project-by-project basis [4].

In Microsoft, it is clear that for a project to be successful, it would require teamwork by everyone in the organisation, as in [3]. Members of an organisation must meet frequently and work together and build on each other's ideas and strengths. Haas (2002) stresses that team members are the ones who must access and apply distributed knowledge effectively [5].

In addition, good teamwork is one of the basic preconditions for KM. Team is often the basic unit of learning and distribution of knowledge in an organisation. According to Sydanmaanlakka (2002), if the distribution of knowledge succeeds well in a team, it will most probably succeed in the whole organisation [6].

Soliman and Spooner (2000) postulate that KM teams are required not only to improve the performance and standing of the enterprise but also to ensure the effectiveness of the KM programme [7]. They also need to educate the people to use the knowledge effectively in the organisation.

In 1995, John Browne, British Petroleum's Group Chief Executive, launched an initiative of the virtual teamwork project to encourage entrepreneurial innovative (Davenport and Prusak, 1998) [8]. British Petroleum's Virtual Teamwork initiative is designed to make it easy for employees and partners to solve various problems in an organisation. The purpose of this Virtual Teamwork Programme was to develop effective ways for members of teams to collaborate across different locations. Their goal was to build a network of people, not a storehouse of data, information or knowledge. The relationships were built through actual and virtual face-to-face meeting.

According to KM Gurus, Nonaka and Takuechi (1995), teams should be cross-functional, involving members from a broad cross-section of different organisational activities [9]. Honda, for example, organised a cross-functional project team to develop the City model and it was composed of people from the sales, development and production departments. The primary goal was to manage development 
activities more systematically by integrating the knowledge and wisdom of ordinary people instead of relying on a few heroes.

In addition, Dutrenit (2000) states that teamwork is established as a new way of organising the work [10]. This was demonstrated by Vitro-Tec staff who worked in cross-functional and cross-divisional teams for product and process developments. The objective was to share knowledge, integrate organisational units, look for synergy and increase the knowledge base.

Drawing from the many successful KM implementations in other organisations and the importance of teamwork, it is recommended that it is implemented in higher learning institutions.

\section{OBJECTIVE OF THE RESEARCH}

The objective of the research is to investigate the success factor and the positive impact of KM implementation in the Mechanical Engineering Division, School of Technology, Tunku Abdul Rahman College (TARC), Malaysia.

\section{Research Methodology}

The study begins with the literature review to identify the importance of the success factor of KM implementation, namely teamwork in higher learning institutions, followed by the KM implementation at TARC. The results of the KM implementation process were evaluated by using in-depth structured interviews with the lecturers of the Mechanical Engineering Division, School of Technology, TARC. Each interview lasted anywhere from 45 minutes to two hours and the focus of those interviews were about teamwork in KM implementation at TARC.

\section{PRACTICAL IMPLEMENTATION OF KM AT TARC}

The success factor, i.e. team work of KM, was implemented at TARC for a period of six months. The authors developed the training materials and conducted KM training in order to encourage the staff to work as a team in the Mechanical Engineering Division, School of Technology, TARC. The following activities were implemented:

1) KM Awareness Training

2) Implementation of success factor (teamwork) of KM

3) Measurement through Structured Interviews - Results

\section{A. KM Awareness Training}

The objective of the training was to familiarise all the staff of the Mechanical Engineering Division with the concepts of $\mathrm{KM}$ and the success factor of KM implementation. The title of the $\mathrm{KM}$ awareness training was "Implementing $\mathrm{KM}$ in Higher Learning Institutions". The following success factor of $\mathrm{KM}$ was conducted to create awareness prior to implementation.

\section{B. Implementation of Success Factor (Teamwork) of KM}

$\mathrm{KM}$ project was implemented in the Mechanical Engineering Division for six months. The model of implementation is as follows:
- A team works across functions and across divisions involving members from different departments. The project team consists of staff from various divisions working together in setting up a new programme and syllabuses. Collaboration of ideas from staff from different backgrounds will help in these projects.

- The team educates other staff on how to use knowledge to improve their work. KM awareness training is provided to all the staff from the Mechanical Engineering Division.

- The team ensures the effectiveness of the KM implementation by measuring and monitoring the progress and the performance of KM. The team is responsible for monitoring the progress of implementation of KM by having follow-up meetings and discussions.

- The team meets regularly to share their knowledge and experiences. Knowledge sharing forums will be held in order to let all the staff share their knowledge and experiences.

- The team works together to form a strong network for effective knowledge transfer. The staff often gather and discuss the latest development in the division.

\section{Measurement through Structured Interviews - Results}

The following are the results of the implementation process which consisted of in-depth interviews with the lecturers from the Mechanical Engineering Division.

The questions are listed as follows:

Question 1: Describe in detail how you have implemented the success factor (teamwork) of KM.

Question 2: What were the problems encountered during the implementation of KM?

Question 3: What are the solutions for the problems encountered?

Question 4: What is the positive impact observed after the implementation of KM?

The results from five interviewees are summarised as follows:

1) Team works in across functions and across divisions involving members from different departments.

- Implementation: The project team (for example, setting up a new course - Mechatronics and Engineering Competitions for students - Robotcon) consists of the staff from different divisions, i.e. the Mechanical Engineering and Electronic Engineering Divisions. Collaboration of ideas from the staff from different backgrounds will help in these projects.

- Problem encountered: Conflicts occurred at the beginning stage. The reason is that they do not know each other very well at the beginning stage.

- Solution: Conflicts solved when they communicated well with each other and had a mutual understanding between them.

- Positive impact: By sharing the knowledge among all the staff from the Electronic Engineering and Mechanical Engineering Divisions, this increases efficiency, quality, creativity and innovation in these projects.

2) Team educates people on how to use knowledge to improve their work.

- Implementation: $K M$ awareness training is conducted for all the staff from the Mechanical Engineering Division. 
The purpose of this training is to educate the staff on the implementation and the benefits of KM.

- Problem encountered: Nil.

- Solution: Nil.

- Positive impact: It can be observed that the quality of staff's performance and efficiency has improved.

3) Team ensures the effectiveness of the KM implementation by measuring and monitoring the progress and the performance of KM.

- Implementation: The team is responsible for monitoring the progress of KM implementation by having follow-up meetings and discussions. The team also measures the $\mathrm{KM}$ performances such as numbers of new and creative ideas generated for the division and faculty.

- Problem encountered: Effectiveness was low at the beginning stage due to lack of motivation.

- Solution: Management suggested putting this indicator into the performance appraisal.

- Positive impact: This increases staff's efficiency, quality of performance, competencies and reputation, reduces cost, and encourages research, creativity and innovation.

4) Team meets regularly to share their knowledge and experiences.

- Implementation: Team meets regularly in knowledge sharing forums, meetings, seminars and workshops to share their areas of expertise.

- Problem encountered: Nil.

- Solution: Nil.

- Positive impact: Different backgrounds and experience of the team members will give rise to the quality of performance, efficiency, creativity and innovation.

5) Team works together to form a strong network for effective knowledge transfer.

- Implementation: Staff work together to share knowledge in setting up the experimental work, new programmes, syllabuses, etc.

- Problem encountered: Not all the staff are free to share knowledge because of the different allocation of their teaching hours.

- Solution: Management allocated two hours a week for the staff to meet with each other. All of them do not have any classes at this particular time. Thus, they are free to form a network for knowledge transfer.

- Positive impact: This increases efficiency and shorten the process of setting up experiments, new programmes and syllabuses.

\section{CONCLUSION AND RECOMMENDATION}

A structured interview was conducted after the implementation of success factor (teamwork) of $\mathrm{KM}$ at TARC. The findings revealed that there is a positive influence of teamwork with a positive impact of KM. However, further empirical research is recommended in this study in order to validate the findings. A survey research is highly recommended.

\section{ACKNOWLEDGMENT}

The authors would like to express their sincere appreciation to TARC for supporting this research. The authors also wish to thank their colleagues at TARC for providing valuable data in this research.

\section{REFERENCES}

[1] K. Choochote, "An analysis of knowledge management process for SMEs in developing countries: A case study of SMEs in India and Thailand," International Journal of Information and Education Technology, vol. 2, no. 3, pp. 239-242, June 2012.

[2] G. Kefela, "Knowledge-based economy and society has vital commodity to countries," International NGO Journal, vol. 5, no. 7, pp. 160-166, 2010.

[3] A. S. McCampbell, L. M. Clare, and S. H. Gitters, "Knowledge management: The new challenge for the $21^{\text {st }}$ century," Journal of Knowledge Management, vol. 3, no. 3, pp. 172-179, 1999.

[4] B. Guay, "Knowledge management is a team sport," Computing Canada, vol. 27, no. 15, pp. 23, 2001.

[5] M. R. Haas, Acting on what others know: Distributed knowledge and team performance, Harvard University, Unpublished, 2002.

[6] P. Sydanmaanlakka, An intelligent organization: Integrating performance, competence and knowledge management, Oxford: Capstone, 2002.

[7] F. Soliman and K. Spooner, "Strategies for implementing knowledge management: Role of human resources management," Journal of Knowledge Management, vol. 4, no. 4, pp. 337-345, 2000.

[8] T. H. Davenport and L. Prusak, Working knowledge: How organisations manage what they know, Boston, MA: Harvard Business School Press, 1998.

[9] I. Nonaka and H. Takuechi, The knowledge creating company: How Japanese companies create the dynamics of innovation, New York Oxford University Press, 1995.

[10] G. Dutrenit, Learning and knowledge management in the firm, Cheltenham: Edward Elgar, 2000.

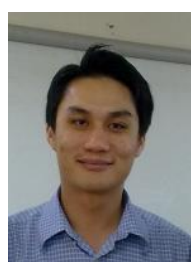

Johnny Chin Fui Chung possesses a Bachelor in Education (Hons) Teaching English as a Second Language (TESL) from University of Exeter, UK in 2001 and a Master in Arts English (specialising in English for Specific Purposes) from Universiti Putra Malaysia, Malaysia in 2004. He is presently reading for his $\mathrm{PhD}$ in Education at Open University Malaysia, Malaysia. He is currently the Head of Languages Division, School of Social Science and Humanities at Tunku Abdul Rahman College, Malaysia.

He possesses vast experience in teaching English and has authored and published, to date, 12 English textbooks and workbooks for schools, colleges and universities in Malaysia. He has also published two papers in the field of science education.

Mr Chin is currently involved in a three-year international research project funded by the European Union Science in Society Framework 7 Programme on Science Education for Diversity. The research project involves six reputable institutions of higher learning from Malaysia, the Netherlands, India, Lebanon, the UK and Turkey.

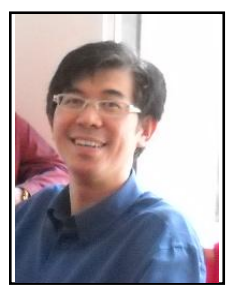

Yip Mum Wai graduated with a Diploma in Materials Engineering from Tunku Abdul Rahman College Malaysia in 1997 and a MSc in Manufacturing Systems Engineering from University of Warwick, U.K. in 1998. In 2008, he was awarded an Engineering Doctorate in Engineering Business Management (specialising in Knowledge Management) from Business Advanced Technology Centre, Universiti Teknologi Malaysia, Malaysia.

$\mathrm{He}$ is a senior lecturer at Tunku Abdul Rahman College, Malaysia. He is also a certified Knowledge Management Facilitator and Practitioner, a certified TRIZ Practitioner, a Senior Member of International Association of Computer Science and Information (IACSIT) and a member of Malaysia TRIZ Innovation Association. He has presented many papers in the field of engineering management especially in $\mathrm{KM}$ in many international conferences in China and Indonesia. He is also a reviewer and an Editorial Board Member for International Journals.

Dr. Yip has a lot of experience in research. He has been given a grant by the Ministry of Higher Learning Institution to conduct a research in the implementation of KK in SME in Malaysia. 


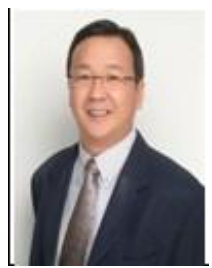

Dominic Lau graduated with a Bachelor of Science in Applied Chemistry from Campbell University, USA in 1991 and a Master of Science (MSc) in Engineering Business Management from University of Warwick, U.K. in 1998. In 2002, he was awarded an Engineering Doctorate in Engineering Business Management from Business Advanced Technology Centre, Universiti Teknologi Malaysia, Malaysia.

$\mathrm{He}$ is a certified Blue Ocean Strategy practitioner and currently the Director of Applied Research Centre of UCSI University, Malaysia. He has successfully completed the Blue Ocean Strategy qualification process administered by the Blue Ocean Strategy-Initiative Centre. $\mathrm{He}$ is a practitioner in the field of quality management system and business management. He is an IATCA registered Lead Assessor (IRCA, QSA \& MRCA), $\mathrm{He}$ is also a registered consultant of the Department of Standard Malaysia and a registered chemist for his sought after skill and expertise in Business Performance Improvement, Total Customer Satisfaction, Tota Quality Management, ISO 9001, ISO 14001, OHSAS 18001, ISO/TS 16949 ISO/IEC 17025, Process Reengineering, Change Management and Strategic Planning. He has written four books in the areas of strategic management, entrepreneurship, and quality assurance. Furthermore, he released his publication of "Blue Ocean Strategy" on 15 successful cases of the application of Blue Ocean Strategy in the Malaysian context. He is the appointed columnist in Malaysian's leading dailies. He is also active in research publications and has written numerous papers in academic journals.

Dr. Lau was awarded as Honouree for The Outstanding Young Malaysian Award in 2002 for the category of Personal Development and Accomplishment and also conferred as Penang Top 10 Outstanding Chinese Youth Award in 2004. With his contribution to the Junior Chamber
International, he has been conferred with JCI Senatorship 2006-Life membership. His passion and interest in knowledge development has earned him an Associate Professor in Universiti Teknologi Malaysia as well as the lecturer and academic supervisor for Warwick University, UK Master Programme students. Dr. Lau also has been appointed as an external examiner for UTM PhD student and Southern College for BBA programme.

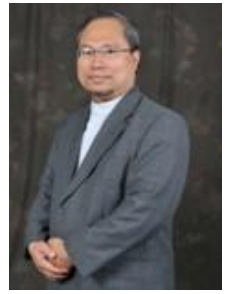

Ahmad Rahman Songip is the Founding Director of Transformation and Risk Management Division, Universiti Teknologi Malaysia (UTM) and an Associate Professor at the Malaysia-Japan International Institute of Technology, UTM, Kuala Lumpur. He is an entrepreneur who practises creativity and innovation. $\mathrm{He}$ is passionate in helping organisations to sharpen and capitalise the latent potential of their greatest asset: the creativity of their human capital. His flagship consulting programme is called VACCINE (Value Creation Acceleration through Creativity and Innovation Experience). VACCINE helps organisation to harvest the minds of their human capital to create quantum leap values to ensure the organisation's long-term survival and sustainability. So far, more than 5,000 participants from more than 500 organisations have benefited from his facilitations.

Dr. Ahmad graduated with BSc (High Honours) and MChE degrees in Chemical Engineering from Illinois Institute of Technology, Chicago, USA as well as Dr.Eng from Kyoto University, Japan. His research interests include the production of hydrogen for fuel cells, the application of zeolite in industry, and the management of creativity, innovation and technology. He supervises more than 30 Masters and Doctorate candidates and has published more than 60 publications. He holds three Intellectual Property rights. 